\title{
Perhitungan Hidrograf Banjir dengan Metode Hidrograf Satuan Sintesis SCS (Soil Conservation Service) di Kota Palembang
}

\author{
Anggi Nidya Sari ${ }^{1}$, Radius Pranoto ${ }^{2}$, Viktor Suryan ${ }^{3}$ \\ ${ }^{1}$ Politeknik Negeri Sriwijaya, ${ }^{2}$ Politeknik Negeri Sriwijaya, ${ }^{3}$ oliteknik Penerbangan Palembang \\ *e-mail: angginidya@polsri.ac.id, radius.pranoto@polsri.ac.id, viktor@poltekbangplg.ac.id
}

\begin{abstract}
Peningkatan jumlah lahan kritis di Indonesia saat ini makin meningkat, tak terkecuali pada daerah Kota Palembang. Peningkatan lahan kritis mengakibatkan berkurangnya volume limpasan air. Perubahan penggunaan lahan di Daerah Aliran Sungai adalah salah satu penyebab meningkatnya lahan kritis. Hal inilah yang memicu timbulnya berbagai permasalahan seperti banjir dan kekeringan. Tujuan dari penelitian ini yaitu mengetahui besaran debit dengan menggunakan metode Hidrograf Satuan Sintetik (HSS) SCS. Perhitungan dengan metode HSS SCS ini diharapkan nantinya dapat memberikan informasi mengenai jumlah debit tertinggi sehingga dapat dicari solusi tepat untuk mengurangi permasalah banjir di Kota Palembang. Hasil penelitian menujukkan bahwa Palembang memiliki curah hujan yang cukup tinggi. Curah hujan yang tinggi ini harus diantisipasi dengan sarana dan prasarana yang baik agar Kota Palembang terhindar dari banjir. Pembangunan system drainase, perawatan system drainase yang telah ada, dan jumlah sumur resapan harus lebih dimaksimalkan. Kenyataan menunjukkan bahwa saat ini fungsi drainase di Kota Palembang sangat tidak optimal, banyak drainase yang tidak berfungsi dengan baik, banyak yang tertimbun, bahkan banyak daerah yang tidak memiliki system drainase sama sekali.
\end{abstract}

Keywords: Hidrograf Satuan Sintetik (HSS), SCS, Debit, Banjir

(1) Licensees may copy, distribute, display and perform the work and make derivative works and remixes based on it only if they give the author or licensor the credits (attribution) in the manner specified by these. Licensees may copy, distribute, display, and perform the work and make derivative works and remixes based on it only for non-commercial purposes.

\section{PENDAHULUAN}

Saat ini Indonesia memiliki lahan kritis mencapai 14 juta Ha. Indonesia belum mampu melakukan rehabilitas lahan dengan baik. Pemerintah Indonesia sampai saat ini hanya mampu merehabilitas sekitar 500.700 ha lahan kritis yang tersebar di pulau-pulau di Indonesia. Sehingga untuk mencapai zero net degradation diperlukan waktu 48 tahun.

Peningkatan jumlah lahan kritis di Indonesia saat ini juga mengakibatkan terganggunya Daerah Aliran Sungai. Perubahan penggunaan lahan di Daerah Aliran Sungai mengakibatkan perubahan debit aliran sungai, jumlah limpasan dan siklus hidrologi.

Dengan bertambahnya jumlah penduduk di Indonesia hal ini mengakibatkan peningkatan kebutuhan manusia akan penggunaan lahan sebagai tempat tinggal, yang mengakibatkan DAS ikut mengalami perubahan fungsi. Perubahan fungsi DAS erat kaitannya dengan berkurangnya tampungan air limpasan hujan, yang mengakibatkan permasalahan seperti banjir, produktivitas tanah menurun, pengendapan lumpur pada waduk dan banyak permasalahan lain.

Informasi atau pemahanam mengenai jumlah atau besarnya hujan efektif atau air limpasan sangat diperlukan dalam menganalisis banjir rancangan. Metode yang bisa digunakan dalam perhitungan banjir rancangan antara lain hidrogarf satuan terukur dan hidrograf satuan sintetis. Untuk menggunakan metode hidrograf satuan terukur kita membutuhkan cukup banyak data, padahal kenyataan dilapangan menunjukkan sangat sulit mendapatkan data yang optimal untuk perhitungan dengan mengguanakan metode 
hidrograf satuan terukur. Maka perlu dilakukan pendekatan lain agar dengan data terbatas kita tetap bisa menghitung banjir rancangan di daerah tersebut. Pada penelitian ini, karena data yang di peroleh sangat terbatas maka digunakan salah satu metode hidrograf satuan sintetis, yaitu metode hidrograf satuan sintesis SCS .

Perhitungan dengan metode SCS ini diharapkan nantinya dapat memberi informasi mengenai jumlah limpasan yang terjadi pada daerah penelitian.

\section{METODE PENELITIAN}

\section{Bagan Alir Penelitian}

Langkah-langkah penelitian secara umum dapat dilihat pada bagan alir berikut:

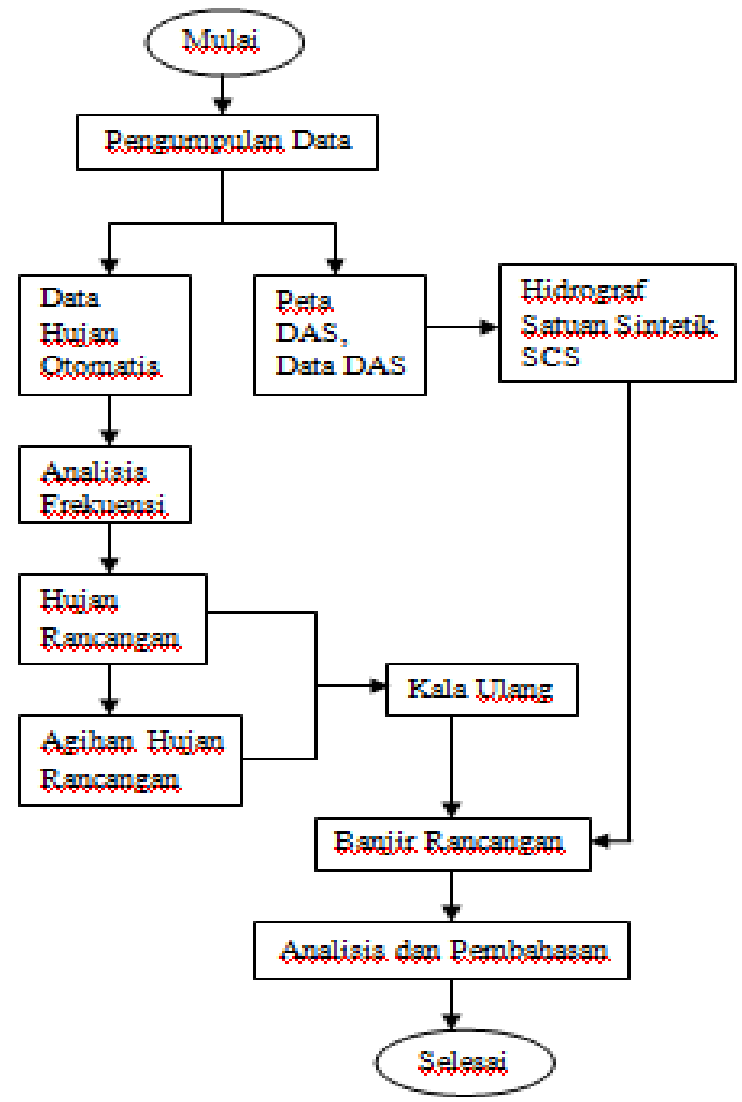

Gambar 1. Bagan Alir Penelitian

\section{Prosedur Penelitian}

Penelitian ini dilakukan dengan menggunakan metode Hidrograf Satuan Sintetik SCS (Soil Conservation Service). Data yang digunakan antara lain, data hujan harian yang berasal dari Stasiun Meteorologi Sultan Mahmud Badaruddin II dan Peta DAS. Adapun tahapan penelitiannya ialah : a. Membaca dan mempelajari semua referensi yang berhubungan dengan penelitian, baik dari buku acuan atau penelitian-penelitian sejenis yang pernah dilakukan sebelumnya,

b. Mengumpulkan semua data sekunder yang diperlukan

c. Penentuan hujan maksimum tahunan DAS. Data hujan yang digunakan adalah data dari tahun 1993 sampai dengan 2018. Data hujan berupa data hujan harian. Data hujan diurutkan lalu diambil satu data maksimum setiap tahunnya.

a. Penentuan Hidrograf Satuan

Kriteria penentuan hidrofraf satuan sebagai berikut:

1. data yang digunakan adalah data hujan harian;

2. baseflow dianggap $5 \mathrm{~mm}$;

3.penentuan hidrograf limpasan langsung;

4. penentuan tinggi limpasan langsung; dan

5. menghitung hujan efektif dengan metode hidrograf satuan sintetik SCS.

b. Penentuan Debit Banjir Rancangan

Untuk penentuan debit banjir rancangan langkah-langkah yang dilakukan ialah:

1. menentukan hujan efektif dengan metode hidrograf satuan sintetik SCS;

2.menentukan hujan rancangan DAS masing-masing kala ulang dengan menggunakan analisis frekuensi;

3. menentukan distribusi hujan rancangan dengan pola hujan rerata; dan

4. menentukan banjir rancangan dari masing-masing hujan efektif dari metode hidrograf satuan sintetik SCS.

\section{Hidrograf Satuan Sintetik (HSS) SCS}

Metode hidrograf satuan sintetik dikembangkan di Amerika Serikat oleh Victor Mockus pada tahun 1972. Ordinat debit merupakan rasio antara debit (q) dengan debit puncak $\left(\mathrm{q}_{\mathrm{p}}\right)$ dan absis waktu merupakan rasio antara waktu $(\mathrm{t})$ dan waktu puncak $\left(\mathrm{t}_{\mathrm{p}}\right)$, dimana waktu naik $\left(\mathrm{T}_{\mathrm{p}}\right)$ dapat diekspresikan sebagai bagian dari waktu puncak tp dan lamanya hujan efektif $t_{r}$.

Koordinat hidrograf SCS (Nugroho 2010, dalam Nushasanah Junia dkk., 2015) 
Tabel 1. Koordinat Hidrograf SCS

\begin{tabular}{cccc}
\hline $\mathrm{t} / \mathrm{T}_{\mathrm{p}}$ & $\mathrm{Q}_{\mathrm{t}} / \mathrm{Q}_{\mathrm{p}}$ & $\mathrm{t} / \mathrm{T}_{\mathrm{p}}$ & $\mathrm{Q}_{\mathrm{t}} / \mathrm{Q}_{\mathrm{p}}$ \\
\hline 0,0 & 0,000 & 1,4 & 0,750 \\
\hline 0,1 & 0,015 & 1,5 & 0,660 \\
\hline 0,2 & 0,075 & 1,6 & 0,560 \\
\hline 0,3 & 0,160 & 1,8 & 0,420 \\
\hline 0,4 & 0,280 & 2,0 & 0,320 \\
\hline 0,5 & 0,430 & 2,2 & 0,240 \\
\hline 0,6 & 0,600 & 2,4 & 0,180 \\
\hline 0,7 & 0,770 & 2,6 & 0,130 \\
\hline 0,8 & 0,890 & 2,8 & 0,098 \\
\hline 0,9 & 0,970 & 3,0 & 0,075 \\
\hline 1,0 & 1,000 & 3,5 & 0,036 \\
\hline 1,1 & 0,980 & 4,0 & 0,018 \\
\hline 1,2 & 0,920 & 4,5 & 0,009 \\
\hline 1,3 & 0,840 & 5,0 & 0,004
\end{tabular}

Dari analasis peta DAS sungai, dapat diketahui beberapa hal penting yang nantinya digunakan dalam menentukan bentuk hidrograf satuan itu yaitu Time Lag $\left(\mathrm{T}_{\mathrm{L}}\right)$, Waktu Puncak $\left(\mathrm{T}_{\mathrm{p}}\right)$ dan Waktu Dasar $\left(\mathrm{T}_{\mathrm{b}}\right)$.

a. Data Karakteristik Fisik DAS

Data yang diperlukan untuk menghitung HSS SCS yaitu antara lain luas DAS, kemiringan sungai dan panjang sungai.

b. Waktu Puncak $\left(\mathrm{T}_{\mathrm{p}}\right)$ dan Waktu Dasar $\left(\mathrm{T}_{\mathrm{b}}\right)$

Rumus yang digunakan untuk menentukan time lag rumus dari Snyder (dengan $\mathrm{Lc}=$ $1 / 2 \mathrm{~L}$ dan $\mathrm{n}=0,3)$ yaitu sebagai berikut:

$\mathrm{T}_{\mathrm{L}}=\mathrm{C}_{\mathrm{t}}\left(\mathrm{L} \cdot \mathrm{L}_{\mathrm{c}}\right)^{\mathrm{n}}$

$\mathrm{T}_{\mathrm{L}}=\mathrm{C}_{\mathrm{t}}\left(\mathrm{L}_{\mathrm{L}} \mathrm{L}_{\mathrm{c}}\right)^{030}$

Dimana :

$\mathrm{C}_{\mathrm{t}}=$ koefisien penyesuaian waktu (biasanya dipakai 1)

$\mathrm{T}_{\mathrm{L}}=$ time lag (jam)

$\mathrm{L}=$ panjang sungai utama $(\mathrm{km})$

$\mathrm{L}_{\mathrm{c}}=$ jarak titik berat ke outlet $(\mathrm{km})$

Untuk durasi hujan satuan $\operatorname{Tr}$ (4 jam), maka waktu puncak HSS SCS didefinisikan sebagai berikut:

$T_{p}=\left(\frac{t_{r}}{2}+T_{L}\right)$

Selanjutnya berdasarkan koordinat tidak berdimensi dari hidrograf satuan SCS, waktu Dasar Hidrograf Satuan (Tb) didefinisikan sebagai berikut:

$\mathrm{Tb}=5$. $\mathrm{Tr}$

c. Debit Puncak

Jika waktu puncak dan waktu dasar diketahui, maka debit puncak hidrograf satuan sintetis akibat tinggi hujan satu satuan $\mathrm{R}=1 \mathrm{~mm}$ yang jatuh selama durasi hujan satu satuan $\operatorname{Tr}=4$ jam, dapat dihitung sebagai berikut:

$Q_{p}=\frac{0,2083 \cdot A}{T_{p}}$

Dimana:

$\mathrm{Q}_{\mathrm{p}}=$ debit puncak $\left(\mathrm{m}^{3} / \mathrm{dtk}\right)$

$\mathrm{A}=$ Luas sungai $(\mathrm{km})$

$\mathrm{Tp}=$ waktu puncak (jam)

\section{HASIL DAN PEMBAHASAN}

\section{Curah Hujan}

Pada penelitian ini curah hujan yang digunakan berasal dari Stasiun Meteorologi Sultan Mahmud Badaruddin II, Kota Palembang. Data hujan yang digunakan ialah data hujan maksimum dari tahun 1993-2018 yaitu selama 26 tahun. Adapun data hujan yang diperoleh dapat dilihat pada table berikut:

Tabel 2. Data Curah Hujan Maksimum Tahunan Periode 1993-2018 di Stasiun Stasiun Meteorologi Sultan Mahmud Badaruddin II, Kota Palembang

\begin{tabular}{|c|c|c|}
\hline No. & Tahun Pengamatan & $\mathrm{R}_{\max }(\mathrm{mm})$ \\
\hline 1 & 1993 & 82,40 \\
\hline 2 & 1994 & 106,60 \\
\hline 3 & 1995 & 116,40 \\
\hline 4 & 1996 & 100,00 \\
\hline 5 & 1997 & 98,70 \\
\hline 6 & 1998 & 107,40 \\
\hline 7 & 1999 & 98,80 \\
\hline 8 & 2000 & 135,60 \\
\hline 9 & 2001 & 120,20 \\
\hline 10 & 2002 & 172,20 \\
\hline 11 & 2003 & 82,80 \\
\hline 12 & 2004 & 119,40 \\
\hline 13 & 2005 & 127,20 \\
\hline 14 & 2006 & 143,30 \\
\hline 15 & 2007 & 121,20 \\
\hline 16 & 2008 & 122,10 \\
\hline 17 & 2009 & 102,80 \\
\hline 18 & 2010 & 133,00 \\
\hline 19 & 2011 & 133,00 \\
\hline 20 & 2012 & 214,10 \\
\hline 21 & 2013 & 126,60 \\
\hline 22 & 2014 & 117,30 \\
\hline 23 & 2015 & 70,30 \\
\hline 24 & 2016 & 105,40 \\
\hline
\end{tabular}




\begin{tabular}{lll}
\hline 25 & 2017 & 101,80 \\
\hline 26 & 2018 & 115,20 \\
\hline
\end{tabular}

\section{Analisis Frekuensi}

Analisis frekuensi dilakukan untuk menetapkan besaran hujan atau untuk menentukan debit kala ulang dengan menggunakan metode statistik. Penetapan seri data dilakukan dengan mengambil data maksimum pada setiap tahun (Annual Maximum Series). Pada proses perhitungan analisis frekuensi ada 4 jenis distribusi probabilitas yang digunakan yaitu : distribusi Normal, distribusi Log-Normal, distribusi LogPearson III dan distribusi gumbel. Serta periode kala ulang yang akan dihitung adalah kalua ulang 5, 10, 20, 50, 100 dan 1000 tahun.

Pada keempat distribusi ini kita akan melakukan uji kecocokan dengan menggunakan uji Chi-Kuadrat dan uji SmirnoKolmogorov. Dari hasil pengujian diperoleh bahwa distribusi yang digunakan yaitu distribusi Gumbel. Hasil perhitungan analisis frekuensi dapat dilihat pada table di bawah ini.

Tabel 3. Perhitungan Analisis Frekuensi

\begin{tabular}{cccc}
\hline \multirow{2}{*}{ Probabilitas } & $\begin{array}{c}\text { Kala Ulang } \\
(\mathrm{T})\end{array}$ & \multicolumn{2}{c}{$\begin{array}{c}\text { Karakteristik Debit } \\
\left(\mathrm{m}^{3} / \mathrm{dt}\right) \text { Menurut } \\
\text { Probabilitasnya }\end{array}$} \\
\cline { 2 - 4 } & & $\mathrm{X}_{\mathrm{T}}$ & $\mathrm{K}_{\mathrm{T}}$ \\
\hline 0,2 & 5 & 138,83 & 0,72 \\
\hline 0,1 & 10 & 155,60 & 1,31 \\
\hline 0,05 & 20 & 171,67 & 1,87 \\
\hline 0,02 & 50 & 192,48 & 2,59 \\
\hline 0,01 & 100 & 208,08 & 3,14 \\
\hline 0,001 & 1000 & 259,61 & 4,94 \\
\hline
\end{tabular}

\section{Hidrograf Satuan Sintetik (HSS) SCS (Soil Conservation Service)}

Perhitungan HSS terkoreksi dilakukan dengan menggunakan metode SCS. Variable yang diperlukan antara lain luas DAS, waktu puncak $\left(\mathrm{T}_{\mathrm{p}}\right)$ dan waktu dasar $\left(\mathrm{T}_{\mathrm{b}}\right)$, debit puncak serta koordinat SCS. Hasil perhitungan dapat dilihat pada table berikut:

Tabel 4. Parameter DAS Musi Hilir

\begin{tabular}{cc}
\hline Parameter DAS & DAS Musi Hilir \\
\hline Luas DAS, A (km2) & 22,46 \\
\hline Durasi hidrograf satuan, D (jam) & 1 \\
\hline
\end{tabular}

Tabel 5. Hasil Perhitungan Parameter DAS dengan Menggunakan HSS SCS

\begin{tabular}{lc}
\hline \multicolumn{1}{c}{ Parameter } & Hasil Perhitungan \\
\hline $\mathrm{Q}_{\mathrm{p}}$ (Debit Puncak) & $8,394 \mathrm{~m}^{3} / \mathrm{s}$ \\
\hline $\mathrm{T}_{\mathrm{p}}$ (Waktu Puncak) & $0,744 \mathrm{jam}$ \\
\hline $\mathrm{Tl}_{\mathrm{ag}}$ (Time lag) & $1,488 \mathrm{jam}$ \\
\hline $\mathrm{tc}$ & 2,479 \\
\hline
\end{tabular}

Tabel 6. Hidrograf Satuan Sintetik (HSS) Terkoreksi SCS

\begin{tabular}{|c|c|c|c|c|}
\hline $\mathrm{t}$ & $\begin{array}{c}\text { Time } \\
\text { Ratio }\left(\mathrm{t} / \mathrm{t}_{\mathrm{p}}\right)\end{array}$ & $\begin{array}{c}\text { Discharge } \\
\text { Ratio } \\
\left(\mathrm{q} / \mathrm{q}_{\mathrm{p}}\right)\end{array}$ & $\begin{array}{c}\mathrm{HSS} \\
\left(\mathrm{q} / \mathrm{q}_{\mathrm{p}}\right) \times \mathrm{Q}_{\mathrm{p}}\end{array}$ & $\begin{array}{c}\text { HSS } \\
\text { Terkoreksi }\end{array}$ \\
\hline 0 & 0,0000 & 0,0000 & 0,0000 & 0,0000 \\
\hline 1 & 1,3444 & 0,8245 & 6,9209 & 5,5384 \\
\hline 2 & 2,6888 & 0,0937 & 0,7864 & 0,6293 \\
\hline 3 & 4,0332 & 0,0106 & 0,0890 & 0,0712 \\
\hline \multicolumn{3}{|c|}{$\Sigma$} & 7,7963 & 6,2389 \\
\hline \multicolumn{3}{|c|}{ Tinggi Hidrograf } & 1,2496 & 1,0000 \\
\hline
\end{tabular}

\section{Distribusi Hujan Jam-Jaman}

Lama hujan rata-rata tiap jangkauan kedalaman hujan pada DAS Musi Hilir adalah 4 jam. Karena data yang tersedia adalah data hujan harian maka untuk menurunkan kurva IDF digunakan persamaan Mononobe. Kemudian didistribusikan dengan metode ABM. Adapun hasil distribusi hujan dapat dilihat pada Tabel di bawah ini:

Tabel 7. Distribusi Hujan Jam-Jaman dengan Kala Ulang 5 Tahun

\begin{tabular}{cccccc}
\hline $\mathrm{t}$ & It (mm/jam) & $\mathrm{P}(\mathrm{mm})$ & Delta & ABM & $\begin{array}{c}\mathrm{P}_{5 \text { th }} \\
(\mathrm{mm})\end{array}$ \\
\hline 1 & 87,46 & 87,46 & 87,46 & 22,73 & 12,24 \\
\hline 2 & 55,10 & 110,19 & 22,73 & 87,46 & 76,97 \\
\hline 3 & 42,05 & 126,14 & 15,95 & 15,95 & 5,46 \\
\hline 4 & 34,71 & 138,83 & 12,69 & 12,69 & 2,21 \\
\hline
\end{tabular}

Tabel 8. Distribusi Hujan Jam-Jaman dengan Kala Ulang 10 Tahun

\begin{tabular}{cccccc}
\hline $\mathrm{t}$ & It (mm/jam) & $\mathrm{P}(\mathrm{mm})$ & Delta & ABM & $\begin{array}{c}\mathrm{P}_{10 \mathrm{th}} \\
(\mathrm{mm})\end{array}$ \\
\hline 1 & 98,02 & 98,02 & 98,02 & 25,48 & 14,99 \\
\hline 2 & 61,75 & 123,50 & 25,48 & 98,02 & 87,53 \\
\hline 3 & 47,12 & 141,37 & 17,87 & 17,87 & 7,38 \\
\hline 4 & 38,90 & 155,60 & 14,23 & 14,23 & 3,74 \\
\hline
\end{tabular}

Tabel 9. Distribusi Hujan Jam-Jaman dengan Kala Ulang 20 Tahun

\begin{tabular}{cccccc}
\hline $\mathrm{t}$ & $\begin{array}{c}\mathrm{It} \\
(\mathrm{mm} / \mathrm{jam})\end{array}$ & $\mathrm{P}(\mathrm{mm})$ & Delta & ABM & $\begin{array}{c}\mathrm{P}_{20 \mathrm{th}} \\
(\mathrm{mm})\end{array}$ \\
\hline 1 & 108,15 & 108,15 & 108,15 & 28,11 & 17,62 \\
\hline 2 & 68,13 & 136,26 & 28,11 & 108,15 & 97,66 \\
\hline 3 & 51,99 & 155,98 & 19,72 & 19,72 & 9,23 \\
\hline 4 & 42,92 & 171,67 & 15,70 & 15,70 & 5,21 \\
\hline
\end{tabular}


Tabel 10. Distribusi Hujan Jam-Jaman dengan Kala Ulang 50 Tahun

\begin{tabular}{cccccc}
\hline $\mathrm{t}$ & $\begin{array}{c}\mathrm{It} \\
(\mathrm{mm} / \mathrm{jam})\end{array}$ & $\mathrm{P}(\mathrm{mm})$ & Delta & ABM & $\begin{array}{c}\mathrm{P}_{50 \mathrm{th}} \\
(\mathrm{mm})\end{array}$ \\
\hline 1 & 121,26 & 121,26 & 121,26 & 31,52 & 21,03 \\
\hline 2 & 76,39 & 152,77 & 31,52 & 121,26 & 110,77 \\
\hline 3 & 58,29 & 174,88 & 22,11 & 22,11 & 11,62 \\
\hline 4 & 48,12 & 192,48 & 17,60 & 17,69 & 7,11 \\
\hline
\end{tabular}

Tabel 11. Distribusi Hujan Jam-Jaman dengan Kala Ulang 100 Tahun

\begin{tabular}{cccccc}
\hline $\mathrm{t}$ & $\begin{array}{c}\mathrm{It} \\
(\mathrm{mm} / \mathrm{jam})\end{array}$ & $\mathrm{P}(\mathrm{mm})$ & Delta & ABM & $\begin{array}{c}\mathrm{P}_{100 \mathrm{th}} \\
(\mathrm{mm})\end{array}$ \\
\hline 1 & 131,08 & 131,08 & 131,08 & 34,07 & 23,58 \\
\hline 2 & 82,58 & 165,15 & 34,07 & 131,08 & 120,59 \\
\hline 3 & 63,02 & 189,05 & 23,90 & 23,90 & 13,41 \\
\hline 4 & 52,02 & 208,08 & 19,03 & 19,03 & 8,54 \\
\hline
\end{tabular}

Tabel 12. Distribusi Hujan Jam-Jaman dengan Kala Ulang 1000 Tahun

\begin{tabular}{cccccc}
\hline $\mathrm{t}$ & $\begin{array}{c}\text { It } \\
(\mathrm{mm} / \mathrm{jam})\end{array}$ & $\mathrm{P}(\mathrm{mm})$ & Delta & ABM & $\begin{array}{c}\mathrm{P}_{1000 \text { th }} \\
(\mathrm{mm})\end{array}$ \\
\hline 1 & 163,54 & 163,54 & 163,54 & 42,51 & 32,02 \\
\hline 2 & 103,03 & 206,05 & 42,51 & 163,54 & 153,06 \\
\hline 3 & 78,62 & 235,87 & 29,82 & 29,82 & 19,33 \\
\hline 4 & 64,90 & 259,61 & 23,74 & 23,74 & 13,25 \\
\hline
\end{tabular}

\section{Hidrograf Banjir SCS}

Perhitungan hidrograf banjir dilakukan dengan menggunakan Hidrograf Satuan Sintetik SCS. Baseflow ditetapkan sebesar 5 mm Hasil perhitungan hidrograf satuan sintetik SCS dapat dilihat pada Tabel dan Grafik di bawah ini:

Tabel 13. Hidrograf Banjir SCS dengan Kala Ulang 5 Tahun

\begin{tabular}{ccccc}
\multicolumn{5}{c}{ Kala Ulang 5 Tahun } \\
\hline $\begin{array}{c}\mathrm{t} \\
\text { jam })\end{array}$ & $\begin{array}{c}\text { HSS } \\
\text { terkoreksi } \\
(1 \mathrm{~mm} / \mathrm{jam})\end{array}$ & $\begin{array}{c}\text { QLL } \\
\left(\mathrm{m}^{3} / \mathrm{s}\right)\end{array}$ & $\begin{array}{c}\mathrm{BF} \\
(\mathrm{mm})\end{array}$ & $\begin{array}{c}\mathrm{Q}_{5 \text { th }} \\
\left(\mathrm{m}^{3} / \mathrm{s}\right)\end{array}$ \\
\hline 0 & 0,00 & 0,00 & 5 & 5 \\
\hline 1 & 5,54 & 494,11 & 5 & 993,22 \\
\hline 2 & 0,63 & 59,58 & 5 & 124,15 \\
\hline 3 & 0,07 & 6,9 & 5 & 18,80 \\
\hline
\end{tabular}

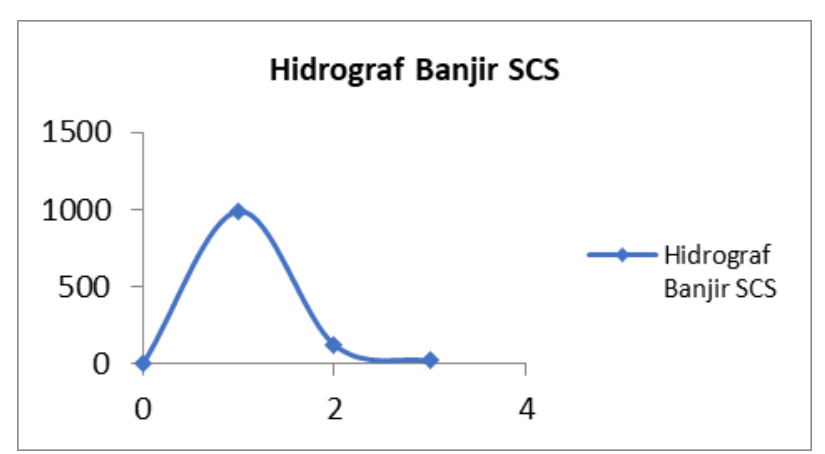

Gambar 2. Hidrograf Banjir SCS dengan Kala Ulang 5 Tahun
Tabel 14. Hidrograf Banjir SCS dengan Kala Ulang 10 tahun

\begin{tabular}{ccccc}
\hline $\begin{array}{c}\mathrm{t} \\
\text { (jam) }\end{array}$ & $\begin{array}{c}\text { HSS } \\
\text { terkoreksi } \\
(1 \mathrm{~mm} / \text { jam })\end{array}$ & $\begin{array}{c}\text { QLL } \\
\left(\mathrm{m}^{3} / \mathrm{s}\right)\end{array}$ & $\begin{array}{c}\mathrm{BF} \\
(\mathrm{mm})\end{array}$ & $\begin{array}{c}\mathrm{Q}_{10 \text { th }} \\
\left(\mathrm{m}^{3} / \mathrm{s}\right)\end{array}$ \\
\hline 0 & 0,00 & 0,00 & 5 & 5 \\
\hline 1 & 5,54 & 567,79 & 5 & 1140,58 \\
\hline 2 & 0,63 & 69,16 & 5 & 143,32 \\
\hline 3 & 0,07 & 8,09 & 5 & 21,19 \\
\hline
\end{tabular}

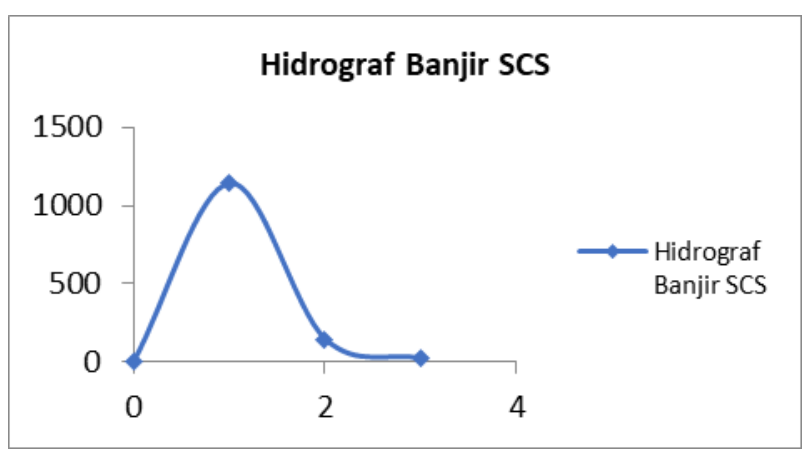

Gambar 3. Hidrograf Banjir SCS dengan Kala Ulang 10 Tahun

Tabel 15. Hidrograf Banjir SCS dengan Kala Ulang 20 Tahun

\begin{tabular}{|c|c|c|c|c|}
\hline $\begin{array}{c}\mathrm{t} \\
(\mathrm{jam})\end{array}$ & $\begin{array}{c}\text { HSS } \\
\text { terkoreksi } \\
(1 \mathrm{~mm} / \mathrm{jam})\end{array}$ & $\begin{array}{c}\mathrm{QLL} \\
\left(\mathrm{m}^{3} / \mathrm{s}\right)\end{array}$ & $\begin{array}{c}\mathrm{BF} \\
(\mathrm{mm})\end{array}$ & $\begin{array}{c}\mathrm{Q}_{20 \text { th }} \\
\left(\mathrm{m}^{3} / \mathrm{s}\right)\end{array}$ \\
\hline 0 & 0,00 & 0,00 & 5 & 5,00 \\
\hline 1 & 5,54 & 638,47 & 5 & 1281,93 \\
\hline 2 & 0,63 & 78,35 & 5 & 161,70 \\
\hline 3 & 0,07 & 9,24 & 5 & 23,48 \\
\hline
\end{tabular}

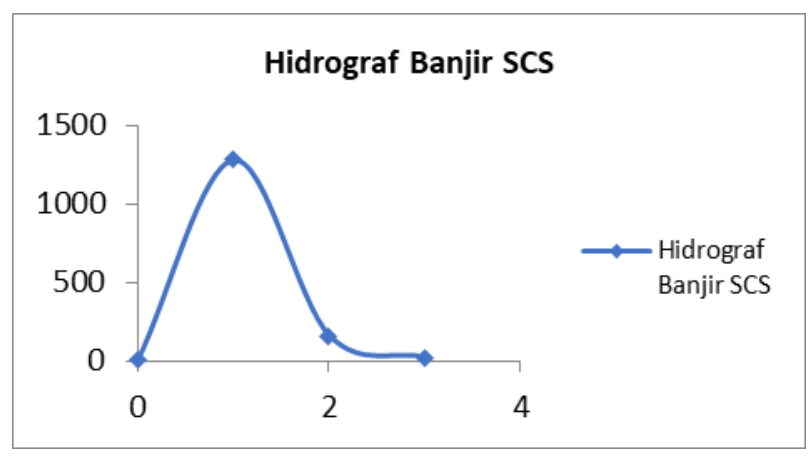

Gambar 4. Hidrograf Banjir SCS dengan Kala Ulang 20 Tahun

Tabel 16. Hidrograf Banjir SCS dengan Kala Ulang 50 Tahun

\begin{tabular}{ccccc}
\hline $\begin{array}{c}\mathrm{t} \\
\text { (jam) }\end{array}$ & $\begin{array}{c}\text { HSS } \\
\text { terkoreksi } \\
(1 \mathrm{~mm} / \text { jam })\end{array}$ & $\begin{array}{c}\text { QLL } \\
\left(\mathrm{m}^{3} / \mathrm{s}\right)\end{array}$ & $\begin{array}{c}\mathrm{BF} \\
(\mathrm{mm})\end{array}$ & $\begin{array}{c}\mathrm{Q}_{50 \text { th }} \\
\left(\mathrm{m}^{3} / \mathrm{s}\right)\end{array}$ \\
\hline 0 & 0,00 & 0,00 & 5 & 5,00 \\
\hline 1 & 5,54 & 729,95 & 5 & 1464,90 \\
\hline 2 & 0,63 & 90,25 & 5 & 185,50 \\
\hline 3 & 0,07 & 10,72 & 5 & 26,44 \\
\hline
\end{tabular}




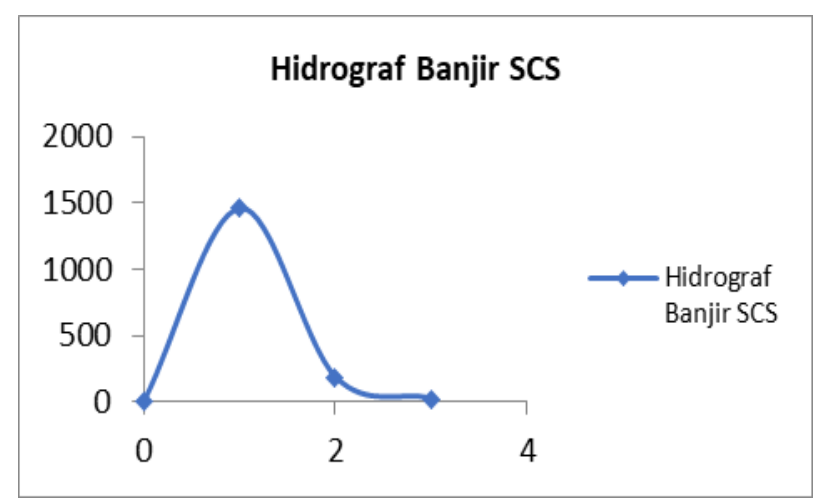

Gambar 5. Hidrograf Banjir SCS dengan Kala Ulang 50 Tahun

Tabel 17. Hidrograf Banjir SCS dengan

Kala Ulang 100 Tahun

\begin{tabular}{ccccc}
\hline $\begin{array}{c}\mathrm{t} \\
\text { jam })\end{array}$ & $\begin{array}{c}\text { HSS } \\
\text { terkoreksi } \\
(1 \mathrm{~mm} / \mathrm{jam})\end{array}$ & $\begin{array}{c}\mathrm{QLL} \\
\left(\mathrm{m}^{3} / \mathrm{s}\right)\end{array}$ & $\begin{array}{c}\mathrm{BF} \\
(\mathrm{mm})\end{array}$ & $\begin{array}{c}\mathrm{Q}_{100 \text { th }} \\
\left(\mathrm{m}^{3} / \mathrm{s}\right)\end{array}$ \\
\hline 0 & 0,00 & 0,00 & 5 & 5,00 \\
\hline 1 & 5,54 & 798,51 & 5 & 1602,01 \\
\hline 2 & 0,63 & 99,17 & 5 & 203,34 \\
\hline 3 & 0,07 & 11,83 & 5 & 28,66 \\
\hline
\end{tabular}

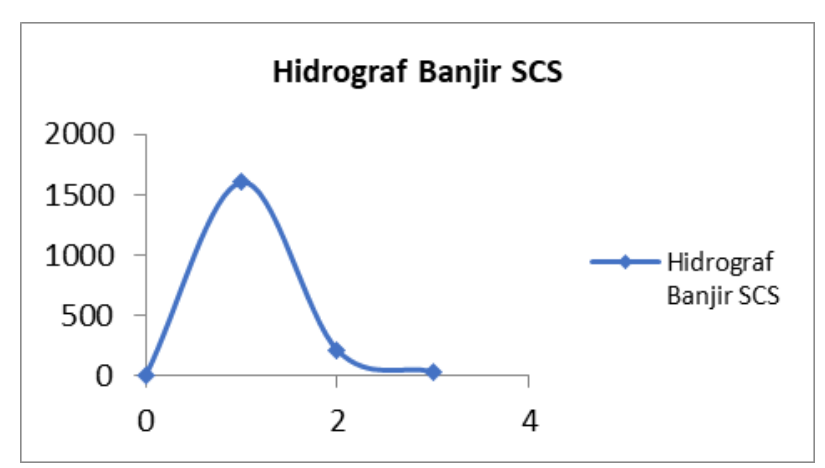

Gambar 6. Hidrograf Banjir SCS dengan

Kala Ulang 100 Tahun

Tabel 18. Hidrograf Banjir SCS dengan Kala Ulang

1000 tahun

\begin{tabular}{ccccc}
\hline $\begin{array}{c}\mathrm{t} \\
\text { jam })\end{array}$ & $\begin{array}{c}\text { HSS } \\
\text { terkoreksi } \\
(1 \mathrm{~mm} / \mathrm{jam})\end{array}$ & $\begin{array}{c}\text { QLL } \\
\left(\mathrm{m}^{3} / \mathrm{s}\right)\end{array}$ & $\begin{array}{c}\mathrm{BF} \\
(\mathrm{mm})\end{array}$ & $\begin{array}{c}\mathrm{Q}_{100 \text { th }} \\
\left(\mathrm{m}^{3} / \mathrm{s}\right)\end{array}$ \\
\hline 0 & 0,00 & 0,00 & 5 & 5,00 \\
\hline 1 & 5,54 & 1025,03 & 5 & 2055,05 \\
\hline 2 & 0,63 & 128,63 & 5 & 262,26 \\
\hline 3 & 0,07 & 15,50 & 5 & 36,00 \\
\hline
\end{tabular}

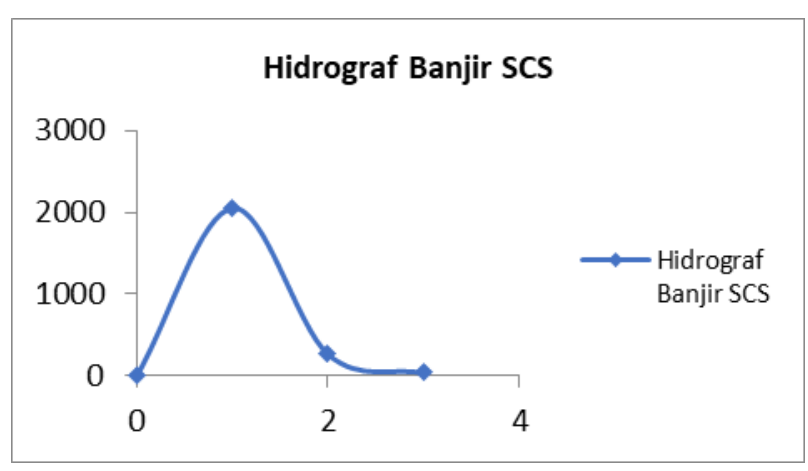

Gambar 7. Hidrograf Banjir SCS dengan Kala Ulang 1000 Tahun

Dari hasil perhitungan hidrograf banjir diketahui bahwa Kota Palembang memiliki curah hujan yang cukup tinggi. Hal ini seharusnya diimbangi dengan sarana dan prasarana drainase yang baik agar Kota Palembang bebas dari banjir. Namun sayangnya di banyak tempat di Kota Palembang drainase masih sangat sedikit, ada yang tidak berfungsi karena tertimbun bahkan ada yang tertutup bangunan. Inilah yang menyebabkan beberapa daerah di Palembang sangat rentan terhadap banjir. Durasi hujan yang tidak terlalu lama namun dengan intensitas tinggi sering mengakibatkan genangan bahkan banjir dimana-mana. Genangan yang paling banyak ditemukan ialah di daerah jalan raya, padahal jalan raya harusnya di design agar terbebas dari genangan, genangan sangat berbahaya bagi pengendara kendaraan bermotor.

\section{KESIMPULAN DAN SARAN}

Perhitungan hidrograf banjir di Kota Palembang menggunakan metode Hidrograf Satuan Sintetik SCS, digunakan metode ini dikarenakan sangat minimnya data yang diperoleh. Dari gambaran hidrograf banjir diketahui bahwa Kota Palembang memiliki curah hujan yang cukup tinggi. Curah hujan yang tinggi ini jika tidak diantisipasi dengan baik dapat mengakibatkan banjir pada saat musim hujan. Untuk mengurangi kejadian banjir harus diupayakan penangan yang maksimal, seperti pembangunan system drainase yang baik, perawatan drainase yang telah ada, memperbanyak daerah resapan. 


\section{DAFTAR PUSTAKA}

Chow, V.T., Maidment, D.R., and Mays, L.W., (1988). Applied Hydrologi. New York: McGraw-Hill Book Company.

Harto, Sri. (2009). Hidrologi: Teori, Masalah, Penyelesaian. Yogyakarta: Nafri Offset.

Marlina, A., \& Andayani, R. (2018). Model Hidrologi Untuk Prediksi Banjir Kota Palembang. Prosiding Seminar Nasional Hari Air Dunia, e-ISSN 2621-7449.

Putri, R. S. W., \& Ayu, D. S. (2018). Analisis Volume Limpasan Dengan Metode
Green-AMPT. Jurnal Nasional Teknologi Terapan, Vol 2. No. 2, 165183.

Sari, A. N., Sujono, J., \& Jayadi, R. (2014). Kajian Beberapa Metode Perhitungan Hujan Efektif dan Pengaruhnya Terhadap Hidrograf Satuan. Tesis: Universitas Gadjah Mada.

Triatmodjo., B., (2010). Hidrologi Terapan. Yogyakarta: Beta Offset. 